\title{
TAMSIL METAFISIK DAN PENGALAMAN MISTIK DALAM SAJAK-SAJAK CINTA GANDRUNG KARYA A. MUSTOFA BISRI
}

\author{
oleh Abdul Wachid B.S \\ STAIN Purwokerto
}

\begin{abstract}
Mustofa Bisri's poetry belongs to the category of poetry that stars from meaning itself but it is also composed from esthetic mystical experiences, It does not rely on the beauty of verbal expression and on language play only. Its esthetic quality also lies on the images of esthetic mystical experiences reflected in his poems. Even if translated into another language, the poems would not lose the esthetic quality.

In accordance with the theory of poetry, the language used in the poems possesses what is often called deceptive simplicity. And in his poems it is assumed to be the result of the basic nature of poetry, that is, indirect expression by way of displacement of meaning, distortion of meaning, and creation of meaning.
\end{abstract}

Keywords: poetry, mystical experience, esthetic quality.

\section{A. PENDAHULUAN}

Membaca sajak-sajak cinta Gandrung karya A. Mustofa Bisri ini, pembaca akan lekas menemui ciri khasnya. Ciri khas perpuisian A. Mustofa Bisri dalam buku Gandrung ini dalam mengekspresikan bahasanya "tidak memperindah kata-kata", seperti halnya dia ungkapkan dalam sajak "Aku Tak Akan Memperindah Kata-kata". Namun, "kesahajaan bahasa sajak" itu tidak berarti kemudian sajaknya jadi gamblang pemaknaannya sebab bagaimanapun puisinya begitu kaya simbol yang memiliki keterkaitan dengan alam pikir religius, bahkan mistisisme Islam (tasawuf). Oleh karenanya, untuk sampai kepada makna batin sajak, pembaca dituntut memiliki wawasan tentang alam pikir yang melatari penciptaan sajaknya. Alam pikir tersebut merupakan perpaduan pengalaman mistik dan pengalaman estetik, yang digambarkan melalui tamsil (perbandingan, perumpamaan) metafisik.

Dalam teori puisi, penggunaan bahasa sajak yang demikian seringkali disebut bersifat "kesederhanaan yang menipu" (deceptive simplicity). Hal itu diasumsikan akibat dari sifat dasar dari puisi, yakni mengungkapkan sesuatu secara tidak langsung (ketaklangsungan ekspresi) melalui penggantian arti (displacing of meaning), penyimpangan arti (distorting of meaning) dan penciptaan arti (creating of meaning) (Riffaterre, 1978:2).

Oleh sebab itu, ungkapan bahasa dalam sajak yang tampaknya sederhana menjadi tidak sederhana apabila pembaca memahami penggantian arti, penyimpangan, dan penciptaan arti dalam sajak itu. Meskipun begitu, alasan ini bersifat estetisme, yang hanya mempertimbangkan aspek bahasa sajak sebagai penggunaan bahasa yang menyimpang dari arti umum (meaning).

Akan tetapi, dangkalnya pemaknaan terhadap suatu sajak tidak saja diakibatkan oleh alasan yang bersifat estetisme. Dalam konteks perpuisian yang mengungkapkan pengalaman religius (religious experience), dangkalnya pemaknaan terhadap sajak lebih diakibatkan si Pemakna tidak dapat mencari rujukan makna terhadap simbol-simbol yang dia maknakan sehingga terjadilah pendangkalan pemaknaan, bahkan menyimpangnya pemaknaan terhadap suatu sajak yang sebenarnya mengungkapkan 
pengalaman religius itu. Demikian misalnya pada sajak A. Mustofa Bisri dari buku puisi Gandrung (2000:21) ini.

\section{Aku Tak Akan Memperindah Kata-kata}

Aku tak akan memperindah kata-kata Karena aku hanya ingin menyatakan Cinta dan kebenaran

Adakah yang lebih indah dari Cinta dan kebenaran

Maka memerlukan kata-kata indah?

Kata "Cinta dan kebenaran" yang dimunculkan dan menjadi pasal dari sajak tersebut, jelas dalam "arti" (meaning), tetapi debatable dalam "makna" (significance). Hal itu sebab memunculkan pertanyaan, "cinta" dalam makna yang mana? dan, "kebenaran" dalam makna yang mana? serta, apa hubungan makna antara "cinta" dan "kebenaran" dalam konteks puisi A. Mustofa Bisri? Di samping itu, mengapa untuk "...menyatakan/ Cinta dan kebenaran//" A. Mustofa Bisri "...tak akan memperindah kata-kata/..."?

Pertanyaan-pertanyaan itu sudah dijawab sendiri oleh A. Mustofa Bisri sebab demi "Sesuatu yang Indah". "Sesuatu yang Indah" itu menurutnya tidak lagi "...memerlukan kata-kata indah" sebab "Cinta dan kebenaran" itu sendiri adalah esensi dari keindahan. Kemudian, kepada siapakah trinitas antara "Cinta dan kebenaran" serta "keindahan" itu dialamatkan? Tentu, dialamatkan kepada Allah, bahkan A. Mustofa Bisri memohon "cinta dan kasih sayang" itu kepada-Nya : "Ya Allah, ya Tuhanku yang Maha Pengasih/ Ya Allah ya Tuhanku yang Maha Penyayang/ Kiranya tak ada permintaan yang lebih besar/ dariku---/ dan tak ada anugerah sebesar apa pun dariMu/ dapat mengurangi kebesaranMu---/ : ya Tuhan, aku memohon cinta dan kasih sayang!//" (Sajak "Doa Pecinta 2", 2000:68).

Alam pikir sajak A. Mustofa Bisri itu diilhami oleh ungkapan terkenal dari Nabi Muhammad SAW bahwa "Sesungguhnya Allah itu Yang Maha Indah dan mencintai keindahan
(InnaLlaha jamil wa yuhibbul jamal)," (hadis dari Abdullah Mas'ud, dikutip dari asy-Syarif, 2003:338; Terj. Hanafi \& Fattah).

Oleh sebab itu, trinitas kata "Cinta dan kebenaran" serta "keindahan" dalam konteks puisi A. Mustofa Bisri harus dipersepsi dan diposisikan sebagai simbol, yang memaknakannya dengan mempertimbangkan teks lain dalam perpuisiannya, dengan mempertimbangkan konteksnya dan mempertimbangkan kontekstualisasinya. Ketiga aspek tersebut, teks, konteks, dan kontekstualisasi, merupakan hakikat dari suatu interpretasi, hermeneutika interpretasi.

\section{B. TRADISI PUISI PROFETIK DAN PUISI SUFISTIK}

Dalam tradisi puisi profetik karya dunia, "tidak memperindah kata-kata" tersebut menjadikan "kesahajaan bahasa sajak", yang hal itu justru menjadi sebuah pilihan. Mengapa "kesahajaan bahasa sajak" itu dipertahankan? Hal ini sebagaimana pernah diungkapkan dengan indah oleh Annemarie Schimmel dalam bukunya Menyingkap Yang-Tersembunyi (Terj. Saini K.M., Cet. I, 2005:40) :

"Sesungguhnya, ketunggalan-nada yang lugas dan lurus dalam pesan profetis memang diperlukan agar isi wahyu yang diterima Nabi dapat dipertahankan kemurniannya, sehingga tidak ada perubahan padanya. Sebagai akibatnya, seorang penyair Muslim yang menulis sajak dalam tradisi "profetis" cenderung menggunakan bentuk yang sederhana untuk menekankan pesannya ke dalam pembacanya."

Dengan demikian, penyair dalam tradisi "profetis" menulis puisinya dengan kesadaran penuh bahwa ia mengurai pengalaman religiositasnya yang eksoterik. Oleh sebab itu, formula sajak dan pengalaman religiositas yang dikabarkannya pun bukanlah "Menyingkap Yang-Tersembunyi", melainkan dunia dan "Puisi-puisi Terang" seperti diistilahkan sendiri oleh A. Mustofa Bisri dalam 
salah satu subbagian buku puisinya Pahlawan dan Tikus (Cet. II, 2005:47).

Akan tetapi, baik penyair profetik maupun penyair mistik pun memiliki kesadaran bahwa mereka berhadapan dengan mukjizat yang berupa bahasa al-Qur'an yang tidak mungkin ditandingi. Oleh sebab itu, para penyair profetik ataupun para mistikus penyair secara terus-menerus merenungkan al-Qur'an, dengan begitu :

"suatu ingatan yang ter-Qur'an-kan (qoranisation de la memoire) dapat dicapai, yang dengan itu para mistikus kemudian memandang segala sesuatu dari sudut-pandang wahyu. Mereka pun setiap saat mengambil inspirasi alQur'an, dan menerapkan lambanglambangnya ke pengalaman mereka sendiri" (Schimmel, 2005:43).

"Hidup di dalam dan melalui al-Qur'an seperti itu membantu pembentukan pengalaman para mistikus dan bahasa mereka" (Schimmel, 2005:43). Dalam konteks ini, bagaimana dengan perpuisian A. Mustofa Bisri?

Tatkala memasuki dunia keprofetikan, tentu saja sajak A. Mustofa Bisri akan berbeda nuansa, ekspresi kebahasaan, simbolitas, bahkan persepsi dan pemosisian aku-lirik dalam sajak, dibandingkan dengan sajak sufistis (dan sufisme)-nya. Yang paling mudah membedakan antara keduanya ialah tatkala mempersepsi dan memposisikan "aku" di dalam sajak. Dalam konteks keprofetikan, Tuhan dipersepsi dan diposisikan sebagai Yang Maha Transenden ("Jauh di Atas Sana"). Sementara itu, manusia berada di bawah langit, bersimpuh di hamparan bumi dalam kedinginan hidupnya yang membutuhkan uluran kehangatan pelukan Tuhan. Namun, ada tabir di antara keduanya sebab manusia hanyalah makhluk, sedangkan Tuhan adalah Sang Maha Pencipta (Al-Khaliq) atas semua makhluk. Bagaimana mungkin keduanya bisa saling berdekatan? Cukuplah kiranya manusia dalam persepsi dan posisi ini memuja-Nya sebagai Yang Maha Tinggi (Al-Aliyy), Yang Maha
Kuasa (Al-Qadir), Yang Maha Penyiksa manusia yang lalai (Al-Muntaqim), Yang Maha Mematikan (Al-Mumit), dan Nama-nama dan Sifat-sifat-Nya yang maskulin semacam itu. Sudut-pandang keprofetikan ini memang dominan dalam perpuisian A. Mustofa Bisri, terutama sekali dalam buku puisi 1. Ohoi (1991), 2. Tadarus (cet.1, 1993), 3. Pahlawan dan Tikus (1995), 4. Rubayat Angin dan rumput (1995), 5. Wekwekwek: Sajak-sajak Bumilangit (1996), dan dalam buku puisi yang terbit urutan ke-7, Negeri Daging (2002). Sementara itu, buku puisi yang terbit pada urutan ke-6 Sajaksajak Cinta Gandrung (2000), diwarnai oleh sudut-pandang mistisisme Islam.

Tipikal mencitrakan keprofetikan A. Mustofa Bisri itu di antaranya dalam sajak "Ketika Tuhan" dari buku puisi Pahlawan dan Tikus (2005:33). Sajak berikut ini mengkontekstualisasikan teks al-Qur'an sebagai salah satu ciri dari tradisi perpuisian profetik, ketika Tuhan dan para malaikat-Nya berdialog tentang maksud penciptaan manusia (al-Baqarah, 2:30) :

"Perhatikanlah sewaktu Tuhanmu berfirman

kepada para malaikat,

'Aku akan menciptakan khalifah di bumi.'

Mereka bertanya keheranan, 'Mengapa

Engkau akan menciptakan makhluk yang

akan selalu menimbulkan kerusakan

dan pertumpahan darah di bumi,

sementara kami senantiasa bertasbih memuji dan mensucikan Engkau? ‘

Allah berfirman, 'Aku Mahatahu akan hal-hal yang tidak kamu ketahui." 


\section{Ketika Tuhan}

Ketika Tuhan menyampaikan MaksudNya menciptakan manusia Sebagai khalifahNya di dunia Para malaikat pun berkata Tuhan, mengapa Paduka Hendak mencipta Makhluk perusak di sana Penumpah darah semena-mena Sedangkan kita

Terus bertasbih dan memuja Paduka?

Tuhan pun bersabda Aku tahu apa Yang kalian buta Terhadapnya

Ketika sang khalifah benar-benar semena-mena

Merusak dan menumpahkan darah di mana-mana Di dunia

Apakah kita akan membenarkan para malaikat dan berkata

KepadaNya seperti mereka lalu siapakah kita Yang tahu kehendak Sang Pencipta? 1414

Namun demikian, pada tingkat tertentu seorang penyair profetik yang memasuki kehidupan mistik, seperti A. Mustofa Bisri, tidak "sekadar" mengungkapkan bahasa profetis yang bersetia secara normatif kepada kebakuan simbol yang diadopsi dari simbol dalam al-Qur'an. Hal itu sebab pada dasarnya mistikus adalah seorang "petualang mandiri" yang tujuannya adalah keakraban dengan Tuhan (uns). Di dalam keakraban cinta dengan Tuhannya, di tengah malam, seorang mistikus menjelma menjadi seorang kekasih yang memuja Yang Maha Kekasihnya. Oleh sebab itu, dia tidak lagi menyeru dengan "Wahai Tuhanku ....." sebagaimana hal itu dilakukan oleh seorang ulama fikih di tengah umat di siang hari, melainkan dengan bisikan-bisikan seorang pencinta dalam kemesraan yang dalam, "Wahai Kekasihku, wahai Cintaku....."
Demikian halnya A. Mustofa Bisri dalam seluruh sajaknya di dalam buku puisi Gandrung, dia menjelma menjadi seorang mistikus cinta yang sejati, seperti "Sajak Cinta" berikut ini (2000:12-13).

\section{Sajak Cinta}

cintaku kepadamu belum pernah ada contohnya

cinta romeo kepada juliet si majnun qais kepada laila belum apa-apa temu pisah kita lebih bermakna dibanding temu-pisah Yusuf dan Zulaikha rindu-dendam kita melebihi rindu-dendam Adam dan Hawa

aku adalah ombak samuderamu yang lari-datang bagimu hujan yang berkilat dan berguruh mendungmu

aku adalah wangi bungamu luka berdarah-darah durimu semilir sampai badai anginmu

aku adalah kicau burungmu

kabut puncak gunungmu tuah tenungmu

aku adalah titik-titik hurufmu huruf-huruf katamu kata-kata maknamu

aku adalah sinar silau panasmu dan bayang-bayang hangat mentarimu bumi pasrah langitmu aku adalah jasad ruhmu fayakun kunmu aku adalah a-k-u $\mathrm{k}-\mathrm{a}-\mathrm{u}$ $\mathrm{mu}$

Rembang, 30.9.1995 
Ekspresi "petualang mandiri" demi keakraban dengan Tuhan (uns) ini pun berpengaruh kepada ekspresi bahasa sajaknya yang juga mandiri, tak terkecuali sajak di atas, dan karenanya khas, bukan tiruan dari ekspresi bahasa sajak penyair lain sehingga orisinal. Hal itu sebab pada dasarnya setiap perpuisian yang estetik dan orisinal merupakan hasil dari "pengalaman mistik" yang juga estetik dan orisinal, yang mandiri sebab bersifat personal : "cintaku kepadamu belum pernah ada contohnya/ .../ temu-pisah kita lebih bermakna/ dibanding temu-pisah Yusuf dan Zulaikha/...," ungkap A. Mustofa Bisri sedemikian personal, antara Tuhan dan dirinya. Personalitas pengalaman mistik ini yang menuntun kepada personalitasnya ekspresi bahasa sajak seseorang mistikus penyair sehingga ada keunikan yang tidak dimiliki oleh penyair lain.

Boleh jadi, setiap pendakian jalan (thariqah) yang dilalui seorang mistikus (sufi) pada hakikatnya menuju kepada satu puncak yang sama, yaitu Allah. Namun demikian, setiap pengalaman mistik itu bentuk-bentuknya tidaklah sama sehingga prioritas jalan yang ditempuh pun berbeda-beda, karenanya tingkatan-tingkatan (maqamat) yang ditempuh juga memiliki penekanan yang berbeda-beda sehingga menghasilkan pengungkapan mistik yang estetik yang berbeda-beda pula. Oleh sebab itu, selalu saja ada yang baru dan segar dari setiap pengungkapan pengalaman mistik di dalam puisi setiap mistikus penyair.

\section{RITME METAFISIK KE TAMSIL METAFISIK}

Pengalaman mistik-estetik yang mandiri tersebut menghasilkan bahasa sajak mistik-estetik yang mandiri pula, hal itu dapat dimaknakan sebagai "kemerdekaan" berekspresi melalui bahasa "sajak-bebas" agar kebebasan penyair untuk menyimpang dari konvensi kebahasaan dapat dilakukannya (licensia poetica). Hal tersebut juga dilakukan oleh A. Mustofa Bisri pada seluruh sajaknya di dalam buku puisi Gandrung ini bahwa perpuisiannya secara wadag kebahasaan terlihat tidak memiliki keteraturan rima. Hal demikian justru ada maknanya apabila kita mengikuti temuan dari hasil penelitian Hagiwara Sakutaro tentang adanya ritme metafisik (metaphisical rythm) yang terdapat pada setiap puisi yang bagus, terutama sekali pada puisi transendental. Alasan Hagiwara Sakutaro ini dikutip secara panjang oleh Abdul Hadi W.M. bahwa :

Puisi dapat dimaknakan puisi bukan hanya karena keteraturan rima, jumlah suku kata pada setiap larik atau kerat, pendek kata bukan karena susunan formalnya, melainkan karena "semangat puitik" (shisheisin) yang berada di baliknya.

Dalam pengertian yang sempit, menurut Hagiwara Sakutaro, ritme merupakan alunan irama atau gerakan temporal dari bunyi yang menghasilkan efek tertentu terhadap perasaan si pendengar. Dalam puisi, ritme seperti ini ditandai dengan pengaliran unsur-unsur fonetik bahasa seperti aksen, tekanan suara, nada dan lain-lain, yang disebut sebagai "ritme lahir". Tetapi, di samping itu terdapat "ritme dalam" yang memberi pengaruh khusus terhadap perasaan, yakni ritme emotif (emotive rythm), dan dapat membawa pembaca ke alam transendental, yakni ritme metafisik (metaphisical rythm). Setiap sesuatu yang indah, terutama puisi transendental, memiliki ritme metafisik. Ritme metafisik terbentuk oleh makna, keindahan tamsil yang digunakan, penempatan kata-kata sesuai dengan struktur pikiran dan perasaan yang hendak diekspresikan, walaupun bentuk lahirnya kelihatan tidak teratur (2001:207-208; dari Makoto Ueda, Modern Japanese Poets and the Nature of Literature, 1983:167169).

"Setiap sesuatu yang indah, terutama puisi transendental, memiliki ritme metafisik." Ritme metafisik ini di dalam puisi A. Mustofa 
Bisri pertama kali tampak dimunculkan melalui "ritme lahir" berupa "ketidakteraturan tipografi" sehingga di saat membaca satu sajak akan memungkinkan sajak itu dibaca dengan beragam aksen, tekanan nada, dan penjedaan pada saat melakukan pemutusan frase atau kalimat secara berbeda-beda. Di samping itu, "ketidakteraturan tipografi" ini menjadi kesengajaan untuk peloncatan baris (enjambement) sehingga menimbulkan beragam interpretasi makna (poly interpretable) sekalipun hanya bertumpu kepada satu sajak. Sebagaimana "ketidakteraturan tipografi" pada sajak "Seporsi Cinta" berikut ini (2000:33).

\section{Seporsi Cinta}

(Diilhami oleh kekasih yang lapar)

Seporsi cinta

Tak habis dimakan

Berdua, sayang

Seporsi cinta

Bila tak habis dimakan

Dibuang sayang

Baris sajak di atas bisa dibaca dengan penjedaan (ditandai dengan garis miring ), yang pertama : "Seporsi cinta/ Tak habis dimakan berdua/ sayang". Kata "sayang" dengan cara pembacaan demikian dapat dimaknakan sebagai, "jangan disia-siakan".

Pembacaan dengan penjedaan yang kedua : "Seporsi cinta tak habis dimakan berdua, sayang". Pembacaan dengan setarikan nafas ini menjadikan kata "sayang" lebih pasti maknanya, yaitu sebagai sapaan kepada "sang Kekasih".

Tipografi sajak dalam buku puisi Gandrung yang dominan justru disusun secara tidak konvensional sebagaimana sajak "Seporsi Cinta" tersebut, yaitu tidak rata tepi kiri dan tidak rata tepi kanan, melainkan simetris di tengah (center). Akan tetapi, simetris di tengah ini dapat dimaknakan sebagai penampakan tipografi yang seimbang (balance), dan karenanya menimbulkan makna harmoni. Justru karena itu, penulisan puisi menjadi tampak indah dipandang oleh pembaca. Prosentase sajak yang demikian, begitu dominan, ada 38 judul sajak. Hanya ada 1 judul sajak "Cinta Hingga" yang bertipografi rata kanan-kiri (justify), dan selebihnya 5 judul sajak yang bertipografi rata kiri (align lift). Tidak ada satu judul sajak pun yang bertipografi rata kanan (align right) sebagaimana hal ini dijadikan trade merk oleh Binhad Nurrohmat di dalam perpuisiannya, Kuda Ranjang (2004).

Di samping itu, tipografi simetris perpuisian A. Mustofa Bisri ini dapat diposisikan dan dipersepsi sebagai simbol dari upaya aku-lirik manusia untuk melakukan keseimbangan, berdiri di tengah, tidak ekstrem kanan dan tidak ekstrem kiri; memaknai keseimbangan antara yang tersurat (arti) dan yang tersirat (makna), yang wadag dan yang spiritual. Karena keseimbangan ini, maka setiap perilaku aku-lirik manusia tidak dimaksudkan sebagai perbuatan yang sia-sia, seperti dalam menyikapi "Seporsi cinta" yang "Tak habis dimakan/ Berdua...//". Oleh sebab itu, jika "//Seporsi cinta/ Bila tak habis dimakan/", maka janganlah "/Dibuang..." sebab hal itu tentu saja akan "...sayang", akan sia-sia. Padahal, Allah tidak menyukai hal yang sia-sia (mubadzir), "innal mubadzdziriina kaanuu ikhwaanasy syayaatiina" (Sungguh para pemboros betul-betul saudara setan) (al-Qur'an, 17:27).

"Ketidakteraturan tipografi" ini digunakan secara berulang-ulang dalam sajak A. Mustofa Bisri lainnya di dalam buku puisi Gandrung ini sehingga memunculkan ketaraturan makna bagi pembaca. Walaupun bentuk tipografi (bagian dari ritme lahirnya) kelihatan tidak teratur, tetapi karena digunakan secara berulang-ulang, justru memunculkan ritme metafisik yang terbentuk oleh makna simbolitas tipografi tersebut, yakni makna keseimbangan antara yang tersurat dan yang tersirat, yang wadag dan yang spiritual.

Mengapa ritme metafisik menjadi penting tatkala membicarakan nilai kesastraan maupun keagungan pemikiran suatu karya 
sastra? Berbicara pentingnya ritme matafisik ini pada hakikatnya kita membicarakan tentang keindahan pengalaman mistik maupun pengalaman estetik yang dituliskan di dalam karya sastra, khususnya puisi. Hal tersebut secara panjang Abdul Hadi W.M. mengurai pemikiran al-Jili sebagai berikut (2001:76-77).

Al-Jili membagi keindahan sebuah puisi menjadi dua, yaitu keindahan luar (husn) dan keindahan dalam (jamal). Terdapat perbedaan besar antara kedua keindahan ini, walaupun keduanya saling memerlukan. Keindahan luar atau bentuk memang mempunyai daya pukau yang kuat, yang disebut sihir oleh al-Jili. Walaupun memukau, keindahan luar terbatas dan bersifat khusus (particular). Keindahan batin yang di dalam (jamal) kebalikannya adalah tidak terbatas dan universal. Kekuatan jamal terletak pada kandungan hikmahnya, yaitu pengetahuan tentang hakikat kehidupan. Dalam puisi hikmah berfungsi memperkaya batin pembaca (Braginsky, 1992). Karena sifatnya yang tak terbatas dan universal, serta dapat memperkaya batin itulah para penulis sufi lebih mengutamakan jamal dibandingkan dengan husn, tanpa mengecilkan peranan husn. Dalam puisi keindahan batin melahirkan makna. Maknalah yang merupakan struktur batin puisi. Sedang keindahan luar melahirkan shurah, yaitu bentuk yang ada di luarnya. Shurah adalah wakil makna di alam penampakan dan kehadirannya sepenuhnya ditentukan oleh makna. Shurah merupakan struktur fisik sebuah puisi.

Selanjutnya, tentang "ritme metafisik terbentuk oleh makna, ..." itu juga diungkapkan oleh al-Jurjani, sebagai berikut.

"...karena yang diekspresikan seorang penyair di dalam puisinya ialah struktur pikiran dan perasaan serta struktur realitas yang kompleks, maka makna yang diturunkan oleh sebuah puisi ialah makna dari makna-makna (ma'na al-ma'na), yang membentang dari makna luar yang sempit, sampai makna dalam yang luas. Dalam membentuk lapisan-lapisan makna itu peranan tamsil atau citra simbolik sangat prinsip dan penting" (via Hadi W.M., 2001:209).

Tamsil (perbandingan, perumpamaan) metafisik tersebut di dalam puisi A. Mustofa Bisri menimbulkan asosiasi metafisik. Sementara itu, bukan kebetulan dalam buku puisi Gandrung karya A. Mustofa Bisri ini ditemukan judul-judul sajak dengan memakai bahasa Arab, yang dari judulnya sudah menimbulkan asosiasi metafisik dan menjadi kata kunci memasuki dunia tasawuf : "Al'isyq" (2000:15, "Keasyikan" - pen; menurut Jalaluddin Rumi bahwa 'isyq adalah cinta yang tidak terbilang banyaknya [Hadi W.M., 2001:36]), "Hanien" (2000:38; "Yang Dirindukan" - pen.), "Ilhaah 1" dan "Ilhaah 2" (2000:53-54; "Makna" - pen.), "Wakhsyah" (2000:60; "Gelisah" - pen.), "Syauq" (2000:61; "Kerinduan" - pen), "Insijam" (2000:62; "Gandrung" atau "Kepayang" - pen.), "Liqaa" (2000:66; "Pertemuan"-pen).

Jika direnungi penataan urutan sajaksajak tersebut, juga menimbulkan asosiasi metafisik, yakni mencerminkan tingkatan ke tingkatan (maqamat) perjalanan spiritual seorang salik ("salikun", "salikin"= penempuh jalan keruhanian, [Hadi W.M., 2001:432]). Perjalanan keruhanian tersebut adalah " $A l^{\prime}$ 'isyq" ("cinta yang tidak terbilang banyaknya") "Hanien" ("Yang Dirindukan") - "Ilhaah" ("Makna") - "Wakhsyah" ("Gelisah") - "Syauq" ("Kerinduan"), "Insijam" ("Gandrung") "Liqaa" ("Pertemuan"). Urutan ini merupakan jalan tarekat (thariqah) menuju kepada Allah: dimulai dari "cinta yang tidak terbilang banyaknya" kepada Sang "Kekasih"/ "Yang Dirindukan", yaitu Allah. Demi mencapai "Makna" rahasia ketuhanan itu sehingga sang Salik mengalami ke-"Gelisah"-an, mengalami "Kerinduan" yang luar biasa, sampai-sampai 
mengalami "Gandrung". Akhir perjalanan keruhanian ini sampailah kepada "Pertemuan" dengan Allah.

Bandingkan, misalnya, tingkatan keruhanian yang disebutkan oleh Annemarie Schimmel (1981:37-38) dan Abu al-Wafa alTaftazani (1983:85) mencakup : taubat, sabar, raja' (harap), khauf (takut), faqir, zuhud, tauhid (selarasnya kehendak seorang hamba dengan kehendak Ilahi), tawakkul (ketergantungan penuh kepada Tuhan), dan mahabbah (cinta) yang termasuk di dalamnya syauq (rindu), uns (kekariban) dan ridla (rela).

Judul-judul sajak tersebut dalam perpuisian A. Mustofa Bisri berposisi sebagai citra simbolik, yang menimbulkan lapisan makna, dari makna luar yang memberi gambaran realitas empiris terbatas, sampai kepada makna dalam yang mengandung "hikmah" (kebijaksanaan). Oleh sebab itu, dalam hal ini, tamsil (perbandingan, perumpamaan) atau citra simbolik menjadi penting di dalam perpuisian A. Mustofa Bisri sekalipun sajaknya disampaikan dengan "kesahajaan bahasa sajak". Memang, sajaksajak A. Mustofa Bisri adalah "sajak yang tak memperindah kata-kata".

Tamsil (perbandingan, perumpamaan) atau citra simbolik tersebut di dalam perpuisian A. Mustofa Bisri sebagian meneruskan tradisi sajak sufi-penyair sebelumnya (yang akan dibicarakan pada subbab selanjutnya), dan sebagian lainnya merupakan temuan khas A. Mustofa Bisri. Demikian contohnya dalam "Sajak Cinta" (2000:12-13) yang mengawali buku puisi Gandrung, di awal subbab sajak ini telah dikutip lengkap.

aku adalah jasad ruhmu fayakun kunmu

aku adalah a-k-u
k-a-u
mu

Dua bait terakhir sajak tersebut merupakan citra simbolik khas A. Mustofa Bisri, yang menimbulkan asosiasi metafisik dan bersumber dari ungkapan al-Qur'an surah Yasin ayat 82. Dari sajak pertama buku puisi ini pun A. Mustofa Bisri telah mempersiapkan pemakaian tamsil metafisik seperti"...//aku adalah jasad ruhmu/ fayakun kunmu//" sebagai wujud kerinduan (syauq) sekaligus kedekatan (uns) kepada Sang Kekasih. Ungkapan tersebut menggambarkan tawakkul (ketergantungan penuh) kepada Sang Kekasih yang teramat dicintainya sehingga "aku" menjadi tidak ada sebab yang ada hanyalah "k-a-u/mu" (penyatuan mistik $=$ fana $)$.

\section{PUISI YANG BERANGKAT DARI "MENYUSUN DUNIA KATA"}

Sementara itu, memaknai bentuk lahir (shurah) sajak tersebut secara mendalam akan sampai kepada makna batin sajak. Pemaknaan itu pada konteks perpuisian A. Mustofa Bisri, seringkali pembaca dihadapkan kepada penggunaan bahasa sajak dalam "kesederhanaan yang menipu" (deceptive simplicity). Memang, perpuisian A. Mustofa Bisri adalah "sajak yang tak memperindah katakata", sekalipun begitu sajak-sajak A. Mustofa Bisri tetaplah sajak yang indah. Mengapa hal itu bisa demikian?

Dalam hal ini, memang, ada sajak yang berangkat dari "mengindahkan" bahasa, yang dari "permainan bahasa" itulah kemudian sampai kepada makna batin sajak. Sebagaimana dalam proses kreatif Chairil Anwar (1956:110), dalam menemukan ekspresi kebahasaan sajak yang paling pas, dia berprinsip "Kita musti bisa menimbang, memilih, mengupas dan kadang-kadang sama sekali membuang. Sudah itu baru mengumpulsatukan". Dengan begitu, ada keasyikan dalam "menyusun dunia kata" agar sampai kepada dunia makna. Hal yang kurang lebih sama ditemukan dalam proses kreatif Sapardi Djoko Damono (1999:259) :

"Pada umur belasan tahun itu saya menulis puisi seperti tak pernah berhenti; ternyata begitu mengasyikkan menyusun dunia kata sedemikian rupa, hanya agar segi-segi yang tak masuk akal bisa terbaca lagi. 
Dan semakin banyak menulis semakin terasa bahwa yang teramat mengasyikkan ternyata adalah penyusunan dunia kata itu sendiri. Barangkali suatu kebetulan bahwa dalam dunia yang saya susun itu muncul masa kecil saya; barangkali memang ada hubungan yang sangat erat antara yang tak masuk akal dan dunia kata yang disebut puisi itu."

"Menyusun dunia kata" agar sampai kepada dunia makna ini menemukan ekstremnya pada proses kreatif Sutardji Calzoum Bachri (1981: 14) melalui "Kredo Puisi"-nya :

"Menulis puisi bagi saya adalah membebaskan kata-kata, yang berarti mengembalikan kata pada awal mulanya. Pada mulanya adalah Kata. Dan kata pertama adalah mantera. Maka menulis puisi bagi saya adalah mengembalikan kata kepada makna."

"Menyusun dunia kata" agar sampai kepada dunia makna ini juga menemukan ekstremnya pada sajak "Sepisaupi" karya Sutardji Calzoum Bachri (1981: 87) :

\author{
Sepisaupi \\ sepisau luka sepisau duri \\ sepikul dosa sepukau sepi \\ sepisau duka serisau diri \\ sepisau sepi sepisau nyanyi \\ sepisaupa sepisaupi \\ sepisapanya sepikau sepi \\ sepisaupa sepisaupi \\ sepikul diri keranjang duri \\ sepisaupa sepisaupi \\ sepisaupa sepisaupi \\ sepisaupa sepisaupi \\ sampai pisauNya kedalam nyanyi
}

Sengaja dipilih sajak "Sepisaupi" , bukan misalnya sajak berjudul "Luka": 'ha ha' atau sajak berjudul "Kalian": pun. Mengapa hal itu bisa demikian? Kedua judul sajak terakhir berisikan bukan kata atau kalimat bahasa. Di dalam "Kalian" berisikan ungkapan partikel bahasa 'pun", selain itu ada 'lah', 'kah', 'tah'. Sementara itu, di dalam sajak "Luka" berisikan ungkapan konsonan-vokal yang menandai suara orang yang sedang tertawa terbahak, 'ha ha'. Sementara itu, di dalam sajak "Sepisaupi" agar sampai kepada dunia makna, penyair memulai perjalanannya berangkat dari bahasa, "menyusun dunia kata", tetapi sangatlah khas yaitu ada permainan bahasa tatkala "menyusun dunia kata". Hal itu, melalui penggabungan dua kata sekaligus ada bagian dari salah satu kata tersebut yang dihilangkan, dan penggabungan dua kata itu pun dijadikan metafora seperti 'sepisaupa sepisaupi'. Dari ungkapan 'sepisaupa sepisaupi' ini pun juga mengandung irama rima yang menimbulkan asosiasi makna. Singkatnya, sajak semacam "Sepisaupi" karya Sutardji Calzoum Bachri ini menjadi sangat kompleks sebagai peristiwa bahasa sajak, justru dari aspek kesastraannya sajak semacam ini menjadi bernilai sebagai karya agung. Oleh karena itu, apabila sajak semacam itu diterjemahkan ke dalam bahasa lain, maka akan kehilangan keindahannya sebagai karya agung; akan musnah kekhasan persajakan Sutardji Calzoum Bachri yang otentik itu. Kesimpulan ini tidak berlaku bagi sajak Sutardji Calzoum Bachri semacam sajak "Walau", yang dalam spekulasi penulis, boleh jadi menjadi inspirasi Sutardji Calzoum Bachri untuk menulis sajak selanjutnya pasca buku puisi O Amuk Kapak (1981).

\section{E. PUISI YANG BERANGKAT DARI PENGALAMAN MISTIK}

Sementara itu, membaca perpuisian sufi-penyair tampaklah bahwa mereka tidak sekadar "mengindahkan" bahasa di dalam sajak. Sufi-penyair dalam menulis sajak agar sampai kepada dunia makna, tidak memulai perjalanannya dari bahasa atau "menyusun dunia kata", melainkan berangkat dari makna 
itu sendiri yang tersusun dari pengalaman demi pengalaman mistik yang estetik yang dialaminya. Bahasa sajak diposisikan "hanya" sebagai medium dari keindahan pengalaman mistik yang mereka alami. Karena pengalaman mistik itu sekaligus memiliki kualitas pengalaman estetik, maka hal ini yang menuntun bahasa ungkap mereka menjadi bahasa sajak yang estetik pula.

Jadi, bahasa sajak yang estetik itu merupakan cermin keindahan hakiki pengalaman mistik sufi-penyair yang tergambar di dalamnya. Pengalaman mistik ini bagi sufi-penyair menjadi bagian hidup kesehariannya, menjadi mediasi bagi percintaannya dengan Tuhan. Oleh sebab itu, banyak pengakuan sufi-penyair bahwa mereka tidak pernah memaksudkan dirinya sebagai penyair tatkala menulis sajak. Mereka menulis puisi sebab puisi bagian dari komunikasi seorang sufi kepada Tuhan. Dengan begitu, puisi menjadi menggambarkan kemesraan dan ketergantungan penuh kepada Kekasih, dalam mahabbah (cinta) yang diwarnai syauq (rindu), uns (kekariban), dan ridla (rela).

Perpuisian A. Mustofa Bisri termasuk puisi yang berangkat dari makna itu sendiri, yang tersusun dari pengalaman mistik yang estetik yang dialaminya. Oleh karenanya, perpuisiannya tidak menggantungkan diri kepada "mengindahkan" bahasa ataupun "permainan bahasa". Singkatnya, kualitas estetik "puisi"-nya terletak pada pengalaman mistik yang estetik, yang dicitrakan di dalam sajaknya. Oleh karenanya, seandainya sajak semacam ini diterjemahkan ke dalam bahasa lain pun, maka tidak akan "pecah" kualitas estetik "puisi"-nya. Hal demikian berlaku bagi puisi karya agung seperti karya Rabi'ah alAdawiyah, Abu Sa'id, Dzun Nun, Sana'i, Anshari, al-Hallaj, Ibn 'Arabi, Ibnu Faried, Fariduddin Attar, Rumi, Hafiz, Jami', bahkan sampai ke puisi Kahlil Gibran. Untuk di Nusantara, hal demikian berlaku bagi puisi karya agung Hamzah Fansuri, Syamsuddin asSumatrani, Nuruddin ar-Raniri, Abdurrauf Singkel, dan beberapa lainnya. Untuk konteks Indonesia, seperti puisi karya Amir Hamzah,
Abdul Hadi W.M., Taufiq Ismail, Kuntowijoyo, Emha Ainun Nadjib, D. Zawawi Imron, Hamid Jabbar, A. Mustofa Bisri, Ahmadun Y. Herfanda, Ajamuddin Tifani, dan beberapa lainnya.

Sekalipun perpuisian A. Mustofa Bisri adalah "sajak yang tak memperindah katakata", tetapi menjadi sajak yang indah justru sebab pembaca dihadapkan kepada "kesahajaan bahasa sajak", dan harus menggali makna secara intensif jika ingin sampai kepada makna batin sajak. Memaknai sajak A. Mustofa Bisri tidaklah sesederhana bentuk lahir (shurah) sajaknya. Pemaknaan akan sampai makna batin sajak jika pembaca mengetahui di mana simpul makna itu harus diurai : dari makna luar sajak yang tampaknya sempit, menuju makna dalam sajak sehingga mencapai makna dari maknamakna (ma'na al-ma'na). Hal ini dengan memberi interpretasi kepada tamsil (perbandingan, perumpamaan) metafisik sajak.

Selain sajak yang sudah dikutip, berikut ini termasuk sajak penting yang menjadi kunci bagi aktualisasi pengalaman mistik sekaligus pengalaman estetik puisi A. Mustofa Bisri. "Sajak Putih Buat Kekasih" (2001:32) adalah sajak kunci yang menggambarkan tingkatan tasawuf yang sering disebut A. Mustofa Bisri dalam sajaknya : khauf (takut) dan raja' (harap-harap cemas). Keduanya bukan sebab takut neraka dan berharap surga, melainkan demi ma'rifah (pengetahuan ketuhanan) yang berbuah mahabbah (cinta).

\section{Sajak Putih Buat Kekasih}

Aku datang pergi berharap dan kecewa
Berharap dan kecewa
Tapi biarlah
Kasih,
Biar kebersamaan kita dengan
demikian
Abadi.
1998

"Kebersamaan" dengan Kekasih Yang Abadi, itulah yang menjadikan seluruh sajak di dalam buku puisi Gandrung karya A. Mustofa 
Bisri dalam situasi rindu (syauq) yang mengharu-biru. Tentu saja, rindu itu disebabkan oleh cinta yang tak terbilang jumlahnya ('isyq), sebagaimana hal ini digambarkan di dalam sajak dengan judul sama yaitu "Al'isyq" (2000:15-16). Akan tetapi, sebab antara makhluk dan penciptanya (khaliq) tidak memungkinkan di dalam satu dimensi ruang dan waktu, maka kerinduan seorang hamba ini seringkali berujung kepada "berharap" dan "kecewa" sebagaimana digambarkan dalam "Sajak Putih Buat Kekasih" tersebut. Atau, seperti dalam sajak "Hanien" (Yang Dirindukan), kerinduan itu hanya dijawab oleh sepi ".../malam ini/ lagi-lagi kau biarkan sepi/ mewakilimu." Namun, akhirnya sang Pencinta memperoleh jawaban dari usaha-usahanya melalui ibadah sosial dan ibadah ritualnya (sajak "Doa Pencinta 2", 2000:68-69) sekalipun:

Aku tak pantas tapi tetap memohon: Ya Tuhan, anugerahilah aku Cinta dan kasih sayangMu.

Ya Tuhan, Kau kabulkan karena kemurahanMu Atau Kau tolak permohonanku karena Ketidakpantasanku --- Semoga Kau kabulkan --aku tetap bersimpuh di depan pintuMu. Kemana lagi? Amin.

Sekalipun terus dan terus "berharap" sebab "kemana lagi" harapan itu dialamatkan kalau bukan kepada Yang Dicintai, yaitu Sang Kekasih (Allah). Bahkan, dengan "berharap dan kecewa" yang terus-menerus itulah justru "kebersamaan kita dengan demikian/ Abadi" (dengan A-kapital). "Keabadian" ini merupakan muara dari hidup.

\section{F. PENUTUP}

Dari uraian sederhana ini sudah terang bahwa ciri khas perpuisian A. Mustofa Bisri dalam buku Gandrung ini dalam mengekspresi- kan bahasanya "tidak memperindah kata-kata", seperti halnya dia ungkapkan dalam sajak "Aku Tak Akan Memperindah Kata-kata". Namun, "kesahajaan bahasa sajak" itu tidak berarti kemudian sajaknya jadi gamblang pemaknaannya sebab bagaimanapun puisinya begitu kaya simbol yang memiliki keterkaitan dengan alam pikir religius, bahkan mistisisme Islam (tasawuf). Oleh karenanya, untuk sampai kepada makna batin sajak, pembaca dituntut memiliki wawasan tentang alam pikir yang melatari penciptaan sajaknya. Alam pikir tersebut merupakan perpaduan pengalaman mistik dan pengalaman estetik, yang digambarkan melalui tamsil (perbandingan, perumpamaan) metafisik.

\section{DAFTAR PUSTAKA}

Al-Ataftazani, Abu al-Wafa' al-Ghanimi. 1983. Sufi dari Zaman ke Zaman. Terj. Ahmad Rofi' 'Utsmani. Bandung: Penerbit Pustaka.

Asy Syarif, Mahmud bin. 2003. Al-Qur'an Bertutur tentang Cinta, Terj. Yusuf Hanafi \& Abdul Fattah. Yogyakarta: Cahaya Hikmah.

Bachri, Sutardji Calzoum.1981. O, Amuk, Kapak. Jakarta: Sinar Harapan.

Bisri, A. Mustofa. 2000. Sajak-sajak Cinta Gandrung. Rembang: Al-Ibris. . 2005. Pahlawan dan Tikus. Yogyakarta: Hikayat, Cet. II.

Damono, Sapardi Djoko. 1999. Sihir Rendra: Permainan Makna. Jakarta: Pustaka Firdaus.

Hadi W.M., Abdul. 2001. Tasawuf yang Tertindas. Jakarta: Paramadina.

Jassin, H.B. 1956. Chairil Anwar Pelopor Angkatan '45. Jakarta: Gunung Agung.

Riffaterre, Michael. 1978. Semiotics of Poetry. Bloomington: Indiana University Press.

Schimmel, Annemarie. 1981. Dimensi Mistik dalam Islam. Jakarta: Pustaka Firdaus. 2005. Menyingkap Yang-Tersembunyi, terj. Saini K.M. Bandung: Mizan, Cet. I. 